\title{
Innovation Mechanism of the Teaching Mode of Pharmaceutical Main Courses Based on Double-drive Method
}

\author{
Yuan Yuan ${ }^{1}$, Weidong Wang ${ }^{1}$, Yanhong Wang ${ }^{1}$, Mingcong Zhang ${ }^{2}$, Shiqi $\mathrm{Ai}^{1}$, Mingyu $\mathrm{Cao}^{3}$, Di $\mathrm{Wu}^{4}$, Sidan $\mathrm{Li}^{5 *}$
}

\author{
${ }^{1}$ Heilongjiang Provincial Key Laboratory of Environmental Microbiology and Recycling of Argo-Waste in Cold Region, College of Life Science and \\ Technology, Heilongjiang Bayi Agricultural University, Daqing 163319, China \\ ${ }^{2}$ College of Agriculture, Heilongjiang Bayi Agricultural University, Daqing 163319, China \\ ${ }^{3}$ College of Science, Heilongjiang Bayi Agricultural University, Daqing 163319, China \\ ${ }^{4}$ College of Engineering, Heilongjiang Bayi Agricultural University, Daqing 163319, China \\ ${ }^{5}$ Institute of New Rural Development, Heilongjiang Bayi Agricultural University, Daqing 163319, China
}

DOI: $10.36347 /$ sjebm.2020.v07i07.001

| Received: 10.07.2020 | Accepted: 23.07.2020 | Published: 30.07.2020

*Corresponding author: Sidan $\mathrm{Li}$

Abstract

Review Article

Based on the current situation of medical course training in colleges and universities at home and abroad, this paper analyzes the existing problems in the medical course training in China, such as the slow renewal of course content and task, the boring teaching method and the mechanical teaching method, and the serious "Glass Ceiling Effect" of crossdiscipline. Aiming at the path design of the teaching mode of medical courses, this paper explores several main courses' teaching reform and training modes by taking the cultivation of comprehensive medical talents as the breakthrough point and the course setting and content integration as the entry point, striving to innovate the training mode of medical talents and forming a highly operational talent training system.

Keywords: Pharmaceutical course; Dual-drive; Virtual simulation.

Copyright @ 2020: This is an open-access article distributed under the terms of the Creative Commons Attribution license which permits unrestricted use, distribution, and reproduction in any medium for non-commercial use (NonCommercial, or CC-BY-NC) provided the original author and source are credited.

\section{INTRODUCTION}

With the rapid development of the pharmaceutical industry, China has become the world's pharmaceutical production base and the demand for first-class pharmaceutical engineering interdisciplinary talents in the forefront of scientific research, production and management increases sharply.

As the main course of pharmaceutical engineering, Pharmaceutical Engineering plays an important role in cultivating pharmaceutical talents. However, at present, there are the following problems in the teaching of this course in most colleges and universities in China: teachers follow the textbook and lack the consciousness of innovative education; The course content is more theoretical and boring, which is easy to be separated from the practical problems in the production line. The single teaching method is difficult to stimulate students' thirst for knowledge and interest, which seriously restricts the improvement of teaching quality. Based on the above factors, it is imperative to seek for the reform and innovation of the teaching mode of the main courses of pharmaceutical major.
The background of curriculum mode reform and innovation

According to the Outline of The National Plan for Medium - and Long-term Education Reform and Development (2010-2020), local undergraduate institutions should be transformed into applicationoriented universities with the main goal of cultivating high-level vocational application-oriented talents. With the development of national higher talents training, the graduates of pharmaceutical engineering and even the whole pharmaceutical industry are booming, and the pressure of employment competition is increasing. However, employers have increasingly higher requirements on the skills of pharmaceutical talents, and even require graduates to adapt to new positions quickly without long-term technical training. At present, compared with other colleges and universities, the school resources of pharmaceutical majors in our university still have obvious gaps in hardware and software, such as equipment, laboratory construction, faculty team construction and specialty characteristic construction. Besides, the curriculum reform is still in its initial stage, facing a lot of difficulties and needs to do a lot of work. Under the dual pressure of external worries and internal difficulties, it is of great significance to take the core course of Pharmaceutical 
Engineering as a breakthrough point to drive the reform and innovation of other relevant courses, so as to promote the development of the discipline [1].

\section{Current situations of reform and development of curriculum teaching mode at home and abroad}

The task-driven teaching model is put forward on the basis of constructivism, which is characterized by "task-oriented, teacher-led and student-oriented". The research on task-driven teaching mode in foreign countries started earlier, including the compilation of task-driven teaching syllabus, the design of classroom tasks, the principles of task implementation and the stages of task implementation. Domestic research on Task-based Teaching (TBT) began in the 1990s and has gone through a series of processes from theory introduction to practice and then to implementation. The main research content focuses on the theoretical basis, teaching principles and teaching process of TBT. The teaching mode of teamwork originated in the United States of the 1970s. It is a creative and effective teaching theory and strategy system widely used in many countries in the world. A group is a formal group of individuals who collaborate to achieve a goal. According to the characteristics of "team cooperation" teaching mode, some scholars discussed the implementation method, implementation method and implementation significance of team cooperation in practical application, and analyzed the specific application of team cooperation teaching mode in teaching [2].

At present, the task-driven teaching mode and teamwork teaching mode advocated by "doing middle school" are generally recognized by many teaching practitioners. Some scholars organically combined task-driven teaching mode and teamwork teaching mode and proposed new teaching mode, which stimulated students' learning enthusiasm, cultivated students' comprehensive ability and innovation consciousness, and promoted the improvement of teachers' teaching level. Therefore, in the context of regional economic integration, it is particularly necessary and urgent to reform the teaching mode of pharmaceutical Engineering.

\section{Reform and innovation path of main course teaching mode}

Target the theme and conduct reasonable research

On the basis of understanding of pharmaceutical research, market demand, adjust the existing curriculum resources, strengthen the frontier content added both at home and abroad, by optimizing the curriculum knowledge structure, design tasks, creating a task oriented repository, strengthen the actual application platform, optimize the teaching means and methods, reform of examination way, build the pharmaceutical engineering double drive type teaching mode.
Focus on the key points and give consideration to both points and aspects

Taking the major of Pharmaceutical Engineering as the pilot, the multi-disciplinary integration, the highly coordinated integration of pharmaceutical professionals' needs in industrial clusters and local colleges and universities, and the exploration of double-driven innovative teaching mode will input multi-layer resources for curriculum reform and discipline development.

\section{Innovative design, induction and deduction}

This paper investigates the current situation of the teaching system of this course in universities and summarizes and deduces the innovative teaching modes and methods at home and abroad. CDIO theory and TRIZ theory were adopted to design course tasks hierarchically, and relevant knowledge points required for each task were connected. Grasp the content of pharmaceutical enterprise informatization strategic management by reading cases, discussing problems and illustrating case analysis results in groups. Create a task-oriented resource library by utilizing course-related online teaching resources on mooCS, Micro courses, Aicurs and other platforms and combining with teaching apps such as Blue Ink Cloud Class. Fractal box dimension method and interaction analysis method are adopted to update and optimize the existing theoretical and practical teaching system, so as to realize the cooperation of educational curriculum system, practice and guarantee system and reform the course assessment method [3].

\section{Exploration on the cultivation mode of double-drive main course}

Optimize the course knowledge structure and design the course task carefully

List all the important knowledge points of the course, keep up with the pace of development of the pharmaceutical industry, add new techniques and new methods, and design the learning tasks hierarchically, which can be divided into basic learning tasks and extended learning tasks. The basic learning tasks are mainly to achieve the basic teaching objectives, to fully grasp the in-class knowledge, and to complete the requirements of after-class experiments and prescribed internships and practices. Extended learning tasks mainly include introducing extra-curricular knowledge and participating in extra-curricular experiments, internships and practical activities for students with ability to learn. It is mainly in the form of group discussion and driven by "task + team" to stimulate students' interest in learning. At the same time, it focuses on engineering examples and teaches around engineering examples. It aims at application and combines teaching activities with engineering tasks. By connecting relevant knowledge points required to complete each task and presenting a clear learning clue, students can acquire new knowledge in the process of 
completing tasks and improve their ability of independent inquiry learning and teamwork [4].

Create task-oriented resource database and strengthen the application of virtual and real platform

Collection first, teacher team strength, creating a task oriented set a large number of teaching video teaching courseware teaching case for the integration of information technology teaching resource, and publish in class teaching on the APP, such as blue ink cloud class students can use the teaching resources in the repository at any time prepare in advance and after class to consolidate learning content secondly, students are encouraged to dig team teaching resources related to this course, the sort of resources Submitted to the teacher after processing, after waiting for teachers review by released to the repository corresponding section. This way not only enrich the database, provides students with more choice of high-quality learning resources, and improve the students study enthusiasm of the team and the ability to collect information information in addition, still can make full use of lesson lesson for micro love courses curriculum related network teaching resources platform, combined with the existing teaching content system, preferential finishing classified archive, form information repository of task-oriented important development resources at the same time, highlight the characteristics of microorganisms and biological pharmaceutical cold environment, make full use of the school Enterprise practice base emphasizes engineering education, strengthens the construction and application of virtual simulation platform, and makes practice teaching and theory teaching complement each other as shown in Fig.1 (in Chinese).

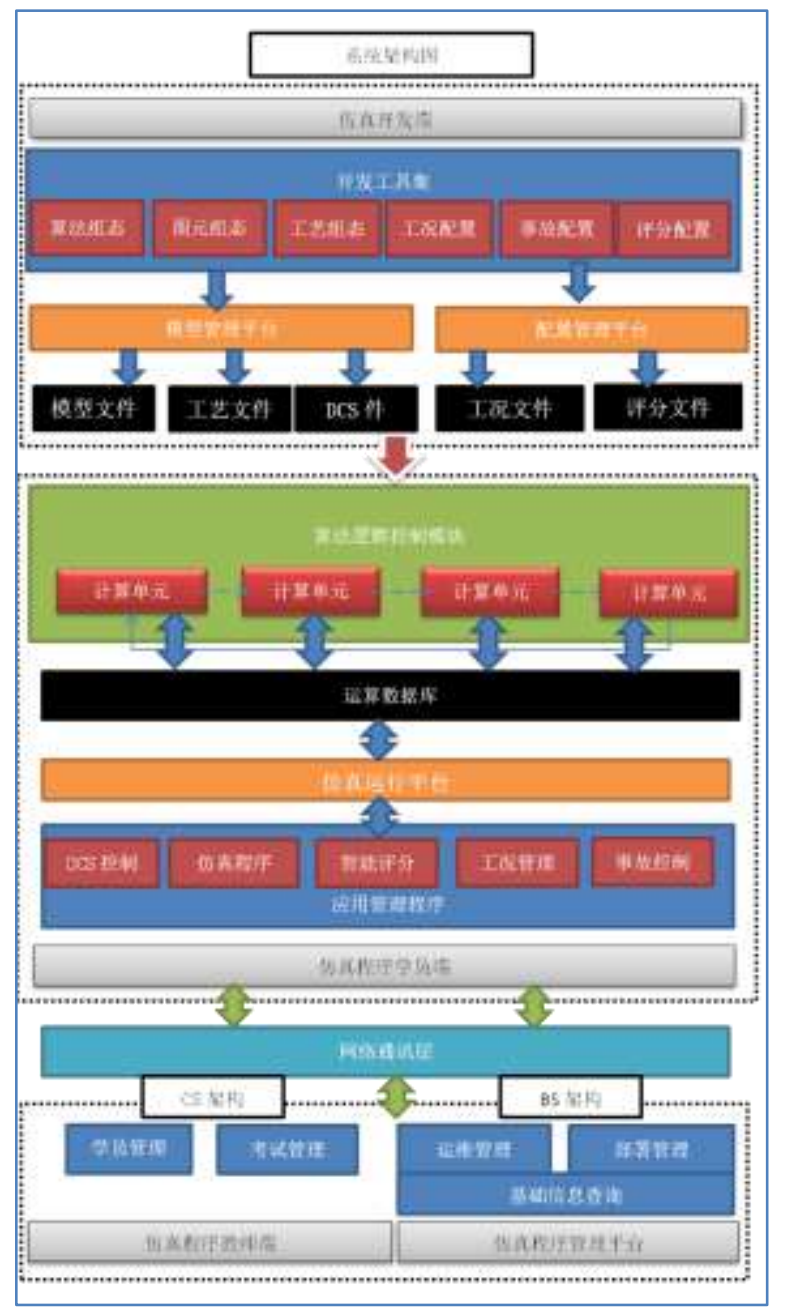

Fig-1: Schematic diagram of virtual and real platform system in Chinese

Optimize the teaching means and methods, reform the curriculum assessment methods

By using modern teaching means, such as Blue Ink Cloud class and MOOC, flipped classroom is implemented to build a teacher-student interactive teaching platform and strengthen the full-program interactive communication mode between teachers and students. By means of virtual simulation platform and multimedia, the real working scene and dynamic working process of pharmaceutical equipment in pharmaceutical enterprises are introduced into the classroom to save teaching cost. At the same time, a 
variety of assessment methods are combined to realize the transformation from attaching importance to knowledge imparting to cultivating ability and improving quality, and attaching importance to students' personality development and creativity cultivation. And for the "task+team" dual - driven teaching mode, the corresponding assessment methods should be modified. First of all, it is necessary to improve the proportion of ordinary scores, which should be $40 \%$, and increase the assessment scope of ordinary scores. It adopts the principle of combining formative evaluation and resultoriented evaluation, emphasizes the completion of all project tasks and functional modules, pays attention to the examination of practical programming ability, pays attention to the evaluation of students' daily learning process, including learning enthusiasm, initiative and real-time, etc., and increases the mutual evaluation among students. For the study of a certain pharmaceutical engineering problem, it is necessary to carry out relevant assessment on the research report, report presentation, etc., and record the usual scores. Increasing classroom discussion and communication, small test scores, so that students more in-depth analysis of the pharmaceutical engineering activities of the conception, design, implementation and operation of each process as shown in Fig.2.

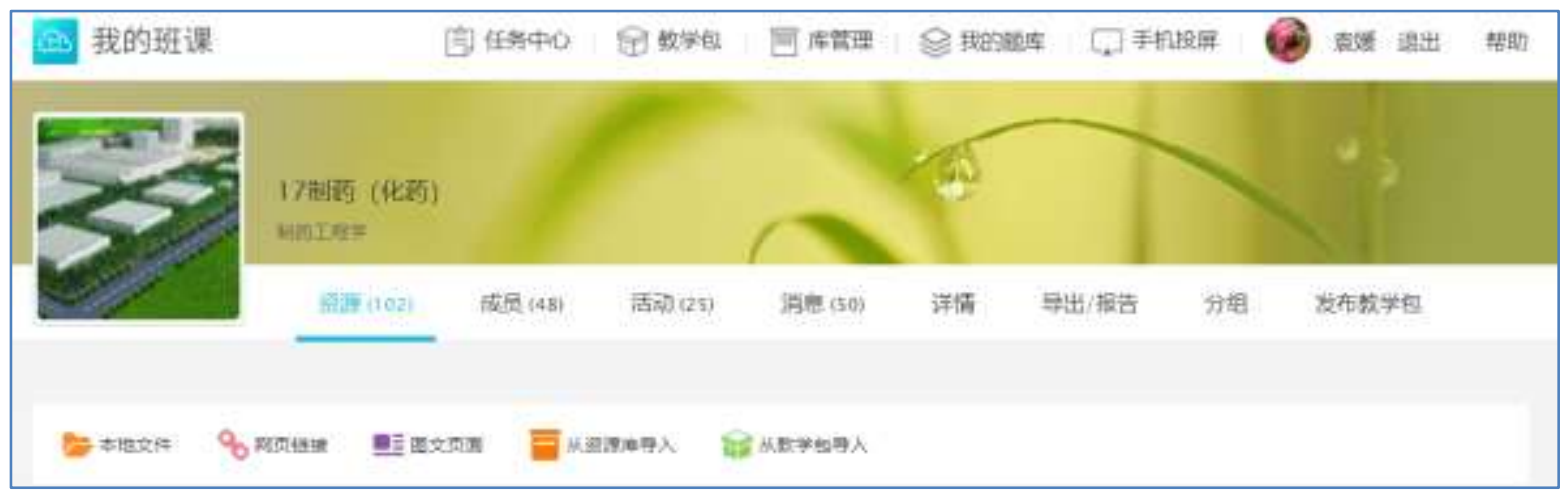

Fig-2: "Pharmaceutical Engineering" Blue Cloud Class platform in Chinese

\section{Interdisciplinary integration, to create medical practical talents}

Comprehensive medical practical talents are medical craftsmen in the new era based on social adaptability. On the basis of the original temperament of keeping improving, paying attention to details, being rigorous and focused, they have the characteristics of multi-dimensional knowledge system, professional focus, simple loyalty, persistence and open innovation. Innovation has become the core driving force of China's economic development. Training medical practical college students with innovative spirit and entrepreneurial ability has become an inevitable requirement for the development of medical higher education, but also an inevitable trend of innovative talent training $[5,6]$.

(1) Deepen the reform of teaching mode. In terms of theoretical value, the cultivation of medical practical talents in colleges and universities can adapt to the adjustment of national economic and industrial structure and promote the construction of regional innovation system by adjusting the cultivation objectives, revising the cultivation scheme, reforming and strengthening the construction of cultivation mechanism. In terms of practical value, the pattern of "public entrepreneurship, peoples innovation" is in full swing, based on the social adaptability of the new era of practical medical talents on the basis of inheriting excellence, mutual support between discipline and profession of interdisciplinary cross major cross training, realize the complementary advantages, resource sharing of the training mode of "multi-win".

(2) Deepen the integration of curriculum training content. According to the disciplines and specialties and grade optimization to build practical medical talents need of compulsory and elective courses, not only pay attention to related subjects such as science, engineering, agronomy specialized interdisciplinary knowledge as a whole set of and pay attention to with the time request, the development of regional economy need to match the qualities and skills of change, through the "+" Internet and virtual simulation platform and made "smart" depth fusion, construct the subject crossing, the overall optimization innovation talents training course system.

\section{CONCLUSION}

By using the virtual simulation platform to combine the virtual and real, the teaching mode of Pharmaceutical Engineering is innovated from the aspects of teaching content, teaching methods and teaching means, etc., to fully mobilize students' learning enthusiasm, master the key points and professional skills of the course, and provide strong pharmaceutical talents and intellectual support for the transformation and development of The City. Comprehensive analysis of local colleges of the curriculum teaching system of pharmaceutical engineering problems, combining with our school pharmaceutical professional characteristics and the new characteristics of regional economic development demand for pharmaceutical talents, use 
interactive virtual simulation platform is open to the mix, collaborative interdisciplinary, cross-sectoral, cross-industry depth cooperation, from with the teaching content, teaching methods and teaching means, etc., exploration and practice of pharmaceutical engineering double drive type teaching mode. In terms of theoretical value, through the cross-integration of multiple disciplines and specialties, the characteristics of cold region environmental microbiology and biopharmaceutical education are highlighted to realize the innovation of "multi-win" teaching mode with complementary advantages and resource sharing, improves teaching quality, and provides the theoretical basis for relevant curriculum reform. In terms of practical value, based on the virtual simulation platform, curriculum reform promotes the construction of curriculum resource base and practice platform, so as to adapt to the adjustment of national pharmaceutical economic and industrial structure, promote the construction of regional pharmaceutical innovation system and the cultivation of innovative pharmaceutical talents.

\section{ACKNOWLEDGEMENT}

This work was supported by Youth Special Project in the 13th Five-Year Plan of Education Science in Heilongjiang Province (GJD1318025); Research Project on Teaching Reform of Degree and Postgraduate Education in Heilongjiang Bayi Agricultural University (YJG201802); Key Project in the 13th Five-Year Plan of Education Science in Heilongjiang Province (GJB1320232, GBB1318088); Teaching Research Project of Heilongjiang Bayi Agricultural University (NDJY1638).

\section{REFERENCE}

1. Sarafianos N, Giannakopoulos T, Nikou C, Kakadiaris IA. Curriculum learning of visual attributes clusters for multi-task classification. Pattern Recognition. 2018 Aug 1; 80:94-108.

2. Kinnebrew J, Segedy J, Biswas G. Integrating Model-Driven and Data-Driven Techniques for Analyzing Learning Behaviors in Open-Ended Learning Environments [J]. IEEE Transactions on Learning Technologies, 2017, 10(2):140-153.

3. Mettas AC, Constantinou CC. The Technology Fair: a Project-based Learning Approach for Enhancing Problem Solving Skills and Interest in Design and Technology Education [J]. International Journal of Technology and Design Education. 2008, 18(1): 79-100.

4. Cai Liping, Xiong Jinbo, Jin Biao, Li Wangbiao. Research on the Construction of the Network Platform for Interdisciplinary Virtual Simulation Experimental System [J]. Research and Exploration in Laboratory. 2018, 37(1):230-233.

5. Li Heng, Jiang Min, Lu Zhenming, Gong Jinsong, Li Hui, Xu Zhenghong, Shi Jinsong. Construction of Virtual Simulation Practical Platform of Pharmaceutical Engineering and Teaching Application [J]. Guangdong Chemical Industry. 2018(1): 201-202.

6. Hebert EP, Landin D, Solmon MA. The Impact of Task Progressions on Students' Practice Quality and Task-Related Thoughts [J]. Journal of Teaching in Physical Education. 2000, 19(3): 338345 . 